The relationship between self-compassion and well-being: A comparison of Turkish and US university students

\author{
Sarı, Tuğba $\bowtie$ \\ Akdeniz University, Turkey (saritugba75@gmail.com)
}

Conoley, Collie

University of California, Santa Barbara, USA (cconoley@education.ucsb.edu)

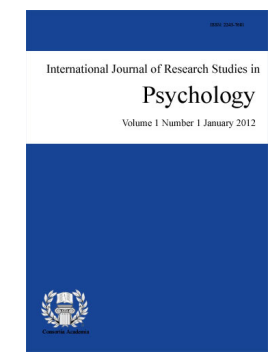

ISSN: $2243-7681$ Online ISSN: $2243-769 X$

OPEN ACCESS

\title{
Abstract
}

Recently self-compassion has become an important construct in psychology. This study furthers the cross-cultural understanding of self-compassion through sampling Turkish and United States (US) students. The participants were 386 university students (273 from Turkey and 113 from the US). The levels of total self-compassion and the sub-scales of the self-compassion measure were compared across the samples, along with self-compassion's correlation with subjective well-being variables. Finally, self-acceptance and positive-relationships were examined as mediators of the correlation between self-compassion and the variables of life satisfaction, positive affect and negative affect for each country. While no statistical differences were found between the samples in levels of total self-compassion, the Turkish sample was significantly higher than the US on two sub-scales (self-kindness and over-identification). Mediation analyses using self-acceptance and positive interpersonal relationships as mediators revealed differences between the Turkish and US students when examining the relationships between self-compassion and the components of subjective well-being. The results are discussed in the context of individualist and collectivist cultures, and the need to re-consider Neff's components of self-compassion for collectivist cultures.

Keywords: cross-cultural differences; self-compassion; life satisfaction; positive affect; negative affect; positive-relationships; self-acceptance 


\section{The relationship between self-compassion and well-being: A comparison of Turkish and US university students}

\section{Introduction}

University students can experience difficulties in their development of identity, independence and responsibility in order to become high functioning adults. Self-compassion, a relatively new construct, has been promoted as central to psychological well-being and life satisfaction of university students (Deniz, Kesici, \& Sümer, 2008). While originating in the Western world by Neff (2003a) self-compassion has gained international attention and research support, especially in the field of positive psychology. With roots in Buddhist philosophy (Neff, 2003b), self-compassion's definition comes directly from compassion. Self-compassion includes being aware of your own pain, mistakes, problems and suffering (Neff, 2004). And reacting to the issues with self-kindness, equanimity, and understanding that fallibility and pain is part of the universal human experience (Neff, 2008).

Self-compassion does not include irresponsibility or egotism but facing and examining issues while engaging in self-kindness and understanding. Specifically, Neff (2003b, 2008, 2011, 2012) includes three elements in self-compassion; self-kindness, common humanity and mindfulness. Self-kindness includes self-understanding with a kind and affectionate attitude. Self-judgment is the opposite of self-kindness, occurring when a person engages in harsh self-judging and self-criticizing. The second element, common humanity means understanding that fallibility and pain in life are not unique to the person. All people go through similar experiences. When unaware of common humanity, isolation or withdrawing from others occurs. The third element of self-compassion is mindfulness. In self-compassion's definition, mindfulness refers to the ability to face distress and accept the feelings or thoughts without being overly influenced by or dissociated from the experience. In the absence of mindfulness, a person may refuse to examine an experience or over-identify with the experience. Over-identification refers to becoming stuck in a problematic feeling or experiencing the feeling so intensely that a person becomes unable to become free of the negative influence.

Self-compassion has been regarded as an emotional regulation strategy for feelings that accompany anxiety and depression in a mindset of self-kindness, curiosity, and with a sense of shared humanity instead of avoiding unpleasant feelings (Folkman \& Moskowitz, 2000). In facilitating a greater willingness to clearly examine issues accompanied by aversive feelings, self-compassion increases an individual's ability to adapt or change, which enables the transformation of negative emotions into positive emotions (Isen, 2000; Neff, Hsieh, \& Dejitterat, 2005). Therefore, self-compassion can protect individuals from the psychological toll of distress, and even facilitate the experience of positive feelings as life gets worse (Leary, Tate, Adams, Allen, \& Hancock, 2007). Because of these benefits, finding interventions that increase the self-compassion levels has been regarded as one of the most important therapeutic goals in the psychological counseling field (Kirkpatrick, 2005).

Many studies have demonstrated the predicted relationship of self-compassion with positive and negative psychological variables. For example self-compassion was found to have a positive relationship with self-control (Neff, 2003a), achievement objectives (Akın, 2008), psychological well-being (Sarıcaoğlu \& Arslan, 2013), self-efficacy (İskender, 2009) academic success (Conway, 2007), forgiveness (Neff, \& Pommier; 2013), social support (Akkaya, 2011; Akın, Kayış, \& Satıc1, 2011), emotional intelligence (İkiz \& Totan, 2012), social connectedness (Neff \& McGehee, 2010), life satisfaction (Neff, 2003b; Tel \& Sar1, 2016), curiosity, discovery, positive emotions (Neff, Rude, \& Kirkpatrick, 2007), and psychological health generally (Neff, Kirkpatrick, \& Rude, 2007). On the other hand, self-compassion was found to have a negative relationship with self-criticism, depression, anxiety, procrastination (Deniz \& Sümer, 2010; Neff, 2003) cognitive distortions in interpersonal relationships (Akın, 2010a), loneliness (Akın, 2010b), internet addiction (Iskender \& Akın, 2011), automatic thoughts (Akın, 2012), psychological vulnerability (Akın, 2014), and procrastination (Williams, Stark, \& Foster, 
Relationship between self-compassion and well-being: A comparison of Turkish and US university students

2008). Similarly, self-compassion was found to be a significant predictor of psychological well-being of Turkish university students (Sarıcıoğlu, 2011). As a consequence of the research summarized above, self-compassion is widely regarded as a significant predictor of well-being and worthy of greater understanding.

The most researched form of well-being has been subjective well-being (SWB). SWB is the level of well-being that a people report experiencing, their own subjective evaluation (Diener, Oishi \& Ryan, 2013). SWB includes the both the cognitive and emotional self-evaluation (Diener, 2000). The cognitive dimension involves life satisfaction, that is, has life been as good as expected or desired. The emotional dimension involves positive and negative affect (Diener, 1984). Life satisfaction research found that psychological variables such as personal tendencies and close relationship are better predictors of life satisfaction than gender, race and income status (Myers \& Diener, 1995). High levels of life satisfaction predict enjoying daily activities, feeling valuable as a person, and having an optimistic attitude toward life (Özer \& Karabulut, 2003).

The emotional self-evaluations of SWB include both positive and negative affect. Positive affect refers to feeling positive emotions such as willingness, energetic, cheerfulness, calmness, peacefulness, liveliness and gratefulness. On the other hand, negative affect refers to feeling negative emotions such as being bored, sad, anxious, worthless, angry and guilty. Intense positive affects involve individual's positive mood, positive attitudes towards other people and life events. Intense negative affects cause individual to perceive his/her life as bad (Diener, 2006). In this regard, individuals' feeling emotions that are more positive and less negative emotions may indicate that they have a high level of subjective well-being (Diener, 2000).

In summary, there are three components of subjective well-being: life satisfaction, positive emotions and negative emotions. It is observed that some combinations have been explained among these three components. For example, according to Diener and Lucas (1999), if an individual express that he/she has a high level of pleasing or positive emotions and a low level of unpleasant or negative emotions, he/she can be defined as a happy individual; if an individual express that he/she has a high level of both positive and negative emotions, he/she can be defined as an overemotional individual. On the other hand, some individuals may have a higher level of life satisfaction despite their rare positive emotions and frequent negative emotions or some individuals may have a lower level of life satisfaction despite their frequent positive emotions and rare negative emotions (Arthaud-Day, Rode, Mooney, \& Near, 2005). In this study, as a result of the existence of these different combinations, it was preferred to consider subjective well-being in terms of its components rather than the total subjective well-being score. We hoped to reach a more detailed understanding of the relationship between self-compassion and well-being across cultures.

Another well-being concept, which is found to have a significant association with self-compassion is psychological well-being. According to Ryff $(1989,2008)$, who brought a comprehensive perspective on psychological well-being, it is necessary to be able to demonstrate the ability to perform some life functions for psychological well-being. Ryff $(1989,1995)$ proposed a model consisting of six elements/functionality domains: self-acceptance (individual's having a positive attitude towards himself/herself and his/her past life), positive-relationships (establishing warm and reliable relationships with others), autonomy (making his/her own decisions, independence, internal control focus), environmental domination (individual's capacity to create an environment suitable for his/her personal and spiritual conditions), individual development (individual's feeling that he/she is constantly developing and growing as an individual) and life purpose (individual's finding life as meaningful) (Ryff, 1989; Ryff \& Keyes, 1995; Keyes, Shmotkin, \& Ryff, 2002). In summary, according to the psychological well-being concept, various life skills explained above enhance the development and functioning of an individual. In this this study we wanted to investigate the possible mediator roles of two domains of psychological well-being 'self-acceptance' and 'positive relationships with others' in the relationship of self-compassion with components of subjective well-being (life satisfaction, positive-negative affect) across individualistic and collectivistic cultures.

To summarize, the positive link between self-compassion and psychological well-being has already been 
Sari, T., \& Conoley, C.

determined and self-compassion is found to be one of the significant determinants of both psychological and subjective well-being in studies conducted in various cultures and geographical regions to this date (Zessin, Dickhauser, \& Garbade, 2015). For instance, statistically significant positive relationships have been found between self-compassion and well-being in America, Thailand and Taiwan cultures (Neff, Pisitsungkagarn, \& Hsieh, 2008), American university students (Neff, Kirkpatrick, \& Rude, 2007; Neff, 2003), Japanese culture (Arimitsu, 2014), Iran culture (Ghorbani, Watson, Chen, \& Norballa; 2012), Spanish culture (Campos et al., 2016), and Turkish culture (Deniz, Kesici, \& Sümer, 2008; Tel \& Sarı, 2016).

\subsection{Self-compassion and culture}

A limited number of intercultural comparison studies have been conducted. For example, Neff, Pisitsungkagarn and Hsieh (2008), in their studies comparing the self-compassion levels of university students continuing their education in Thailand, Taiwan, and the US, determined that the self-compassion levels of Thailand sample were the highest, the self-compassion levels of Taiwan sample were the lowest and self-compassion levels of United States of America sample were between these two samples. According to these findings, it was concluded that self-compassion level depended on cultural items rather than East or West concepts and self-compassion levels in these three cultures were significantly associated with well-being. Similarly, Deniz, Arslan, Özyeşil, and İzmirli (2012) investigated the relationships between self-compassion, life satisfaction and positive-negative affect in Turkish university students and university students from other countries (England, Italy, Poland, Romania, Spain, and Ukrain) and made comparisons between these groups. According to their findings, it was determined that self-compassion levels of Turkish university students were higher than those of other countries. According to the results of the two studies described above, self-compassion levels can vary across cultures, however the relationship between self-compassion and well-being is found to be statistically significant in each culture. However, the studies conducted so far do not reveal the experiences and variables which bring about correlations between self-compassion and well-being in different cultures. Studies that are more detailed are required to determine greater understanding of self-compassion across cultures (Deniz, Arslan, Özyeşil, \& İzmirli, 2012).

Individualism-collectivism is a widely recognized dimension which is known to differentiate societies and accepted as significant concepts to be considered when making intercultural comparisons (Kağıtçıbaşı, 1999). In their well-known theory, Markus and Kitamaya (1991) state that the individuals in collectivist cultures have an interdependent sense of self and they pay attention to the relationships with others, caring about others and social approval, whereas in individualistic cultures, the individuals have an independent sense of self and they emphasize autonomy, individual independence and meeting individual needs. While the emphasis is on being an individual in individualistic culture, the society is in the forefront and social adaptation is important for individuals in collectivist cultures (Biswas-Diener, Diener, \& Tamir, 2004). Similarly, according to the studies conducted on subjective well-being, interdependence and social relationships are more important for individuals to be satisfied with their lives and to feel positive emotions in collectivist cultures while personal achievements and self-confidence are more important for subjective well-being of individuals in individualistic cultures (Uchida, Kitayama, Mesquita, Reyes, \& Morling, 2008; Uchida \& Ogihara, 2012). The emotions are focused on ego in individualistic cultures while the emotions are focused on others in collectivist cultures (Markus \& Kitamaya, 1991). In parallel with this, it is known that the individuals in an American culture, which is regarded as an individualistic culture, tend to place more importance on self-enhancement and positive self-regard (Solomon, Greenberg, \& Pyszczynski, 1991).

Although some of the Turkish people struggle for individualization, recent studies show that Turkish culture continues to be a collectivist culture (Göregenli, 1995, 1997; Hortaçsu, 1997; Kağıtçıbaşı, 2000). For example, in a study İmamoğlu and Yasak (1997) found that emotional dependence was maintained even if financial interdependence was supported in families with upper socio-economic levels. Similarly, in her study on the value of child, Kağıtçıbaşı (1987) concluded that the expectations of the majority of parents from their children was to 'listen to what his/her parents say'. Dependence, obedience and respect are regarded as significant behaviors 
expected from children in Turkish society (Tezcan, 1987). In parallel with this, there are some research findings and opinions suggesting that individuals tend to have a greater focus on external control in Turkish culture (Kuyumcu, \& Güven, 2012; Mocan-Aydın, 2000). In conclusion, as in other collectivist cultures, positive-relationships may be very important for the individuals in Turkish culture.

\subsection{Aim of the study}

Self-compassion has been found to be consistently associated with well-being in both individualistic and collectivist cultures. Significant correlations between self-compassion and psychological and subjective well-being of Turkish (Deniz, Kesici, \& Sümer, 2008) and American university students (Neff, Kirkpatrick, \& Rude 2007; Neff, 2003) have been demonstrated. Despite recent attention on the cross cultural comparisons of the link between self-compassion and well-being, what is influential in the positive relationship between self-compassion and elements of subjective well-being has not been investigated. Different social and cultural variables may cause the predictive effect of self-compassion on well-being to occur through different mediators. In this age of immigration and multiculturalism, there could be a growing need for understanding the relationship of these concepts across cultures.

To further the above-mentioned findings, positive-relationships, which is an important variable in collectivist cultures, may be serving as a mediator between the self-compassion and subjective well-being in the collectivist, Turkish culture. On the other hand, self-acceptance, which is an important psychological variable in individualistic cultures, may be serving as a mediator between the self-compassion and subjective well-being in individualistic American culture. In other words, self-compassion might increase subjective well-being through positive-relationships in collectivist Turkish culture, while self-compassion might increase subjective well-being through self-acceptance in individualistic American culture. Understanding the effect of the mediators in the relationship between the constructs of self-compassion with subjective well-being across cultures could provide insight into the similarities of what self-compassion means across cultures. From this point of view, the general aim of this study is to investigate the mediator roles of positive-relationships and self-acceptance in the relationship between self-compassion and components of subjective well-being (life satisfaction, positive affect, negative affect) among Turkish and US university students. The following research questions were examined:

1. Are there significant differences between the mean scores of the two countries in terms of self-compassion and the components of subjective well-being (life satisfaction, positive affect, negative affect)?

2. Does self-compassion predict the components of subjective well-being (life satisfaction, positive affect, negative affect) in both the Turkey and US sample?

3. Do positive-relations and self-acceptance mediate the relationship between self-compassion and the components of subjective well-being (life satisfaction, positive affect, negative affect) in Turkey and US sample?

\section{Method}

\subsection{Participants}

Participants consisted of 273 Turkish (176 females and 96 male) and 113 US (17 females and 96 male) university students. Turkish participants were students from a large state university in Marmara region of Turkey and US participants were from a large state university in California province. Course credit was given in exchange for participating in the study. 


\subsection{Instruments}

Self-compassion - The Self-Compassion Scale (Neff, 2003b) consists of 26 items and 6 sub-scales: Self-kindness (e.g., "I try to be understanding and patient toward aspects of my personality I don't like"), Self-Judgment subscale (e.g., "I'm disapproving and judgmental about my own flaws and inadequacies"), Common Humanity subscale (e.g., "I try to see my failings as part of the human condition"), Isolation subscale (e.g., "When I think about my inadequacies it tends to make me feel more separate and cut off from the rest of the world"), Mindfulness subscale (e.g., "When something painful happens I try to take a balanced view of the situation"), and Over-Identification subscale (e.g., "When I'm feeling down I tend to obsess and fixate on everything that's wrong."). The self-report measure uses a 5-point Likert-type scale.

The Self-Compassion Scale's validity was investigated by Akın, Akın, and Abac1 (2007) in Turkey, and Neff (2003a) in the US. Both investigations found support for the measure via confirmatory factor analysis. Additionally, the whole scale internal consistency reliability coefficient for both countries was reported as .92. In the present study, Cronbach's alpha coefficient was .77 for the Turkish sample and .91 for the US sample.

Life Satisfaction - The Satisfaction with Life Scale (SWL; Diener, Emmons, Larsen \& Griffin, 1985) is a frequently used measure of global life satisfaction. Consisting of five items (e.g., "My life is close to ideal, in most ways"). The self-report measure uses a 7-point Likert-type scale.

The SWL has been found to correlate strongly with other measures of well-being but is reported as independent from related constructs such as positive affect and loneliness (Diener et. al 1985). The scale was adapted to Turkish by Köker (1991) with equivalent test-retest reliability coefficients $(r=.85)$. In the current study, Cronbach's alpha coefficient was .82 for the Turkish sample and .88 for the USA sample.

Positive and Negative Emotions - The Positive and Negative Affect Scale (PANAS; Watson, Clark \& Tellegen, 1988) consists of two 10-item sub-scales: Positive Emotion (e.g., happy, enthusiastic) and Negative Emotion (e.g., angry, disappointed). The self-report measure uses a 5-point Likert-type scale. The scale was adapted to Turkish by Gençöz (2000) with similar internal consistency of US scale. The Turkish PANAS demonstrated alpha at .83 and .86 respectively for positive and negative emotions and the US PANAS's alpha (Watson, Clark, \& Tellegen, 1988) was .87 for both positive and negative. In the present study, Cronbach's alpha coefficient was .76 for the positive emotions and .72 for the negative emotions in the Turkish sample, and .90 for the positive affect and .72 for the negative affect in the US sample.

Positive-Relationships and Self-Acceptance - The Psychological Well-Being Scale-short form (PWB; Ryff, 1989) was used to obtain measures of Positive-Relationships and Self-Acceptance, which are two of the sub-scales. Each sub-scale consists of 7 self-report items using a 6-point Likert-type scale. The PWB short form was adapted to Turkish by Akın, Demirci, Yıldız, Gediksiz, and Eroglu (2012) who found that the factor analyses supported the scale's validity as did the internal consistency coefficients. The Turkish scale study yielded an internal consistency coefficient for the sub-scales between .87 and .96 and test-retest reliability coefficients were found to be between .78 and .97 . In the present study, Cronbach's alpha coefficient was found .70 for positive-relationships and .75 for self-acceptance in the Turkish sample, and .71 for positive-relationships and .88 for self-acceptance in the US sample.

\subsection{Process}

After receiving institutional, instructor, and participant permission the measures were completed.

\subsection{Data analysis}

The data were analyzed using t-test to examine the first question that explored mean differences between countries. The second question about relationships between self-compassion and the components of subjective 
Relationship between self-compassion and well-being: A comparison of Turkish and US university students

well-being were analyzed using Pearson product moment correlations. The final question examining mediators was analyzed using multiple mediation analyses (Preacher \& Hayes, 2008). Self-acceptance and positive-relationships were examined as mediators for the relationship between self-compassion and the components of subjective well-being (life satisfaction, positive affect and negative affect) as pictured in Figure 1. Data were analyzed using the SPSS 16.00. Preacher and Hayes (2008) SPSS Macro for Multiple Mediation was used to do the mediation analyses.

Figure 1. Graphic representation of the tested mediation model between self-compassion and the three dependent variables (life satisfaction, positive affect \& negative affect) with the two hypothesized mediators, positive-relationships and self-acceptance

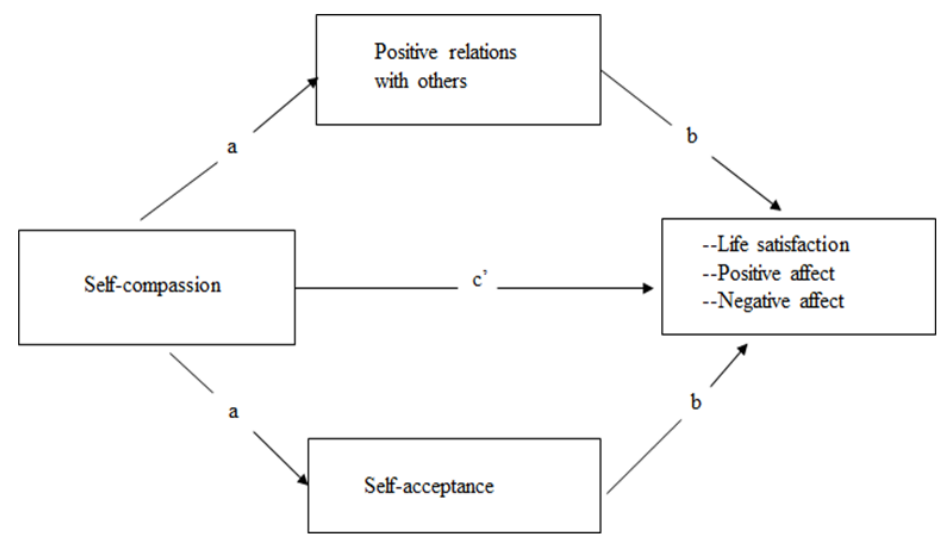

\section{Results}

The first question examined the possible differences between the two countries' samples in terms of self-compassion and the components of subjective well-being (life satisfaction, positive and negative affect). The means and the standard deviations for the self-compassion, life satisfaction, positive affect and negative affect are shown in Table 1. Significant differences were observed on life satisfaction $(d=0.36)$, positive affect $(d=$ $2.79)$ and negative affect $(d=2.89)$ but not for the total self-compassion score. The positive and negative affect means of the Turkish sample were significantly higher than the US sample, whereas the US mean score for life satisfaction was significantly higher than the Turkey sample's mean. The subscales of SCS were also examined to determine if any components of SC differed by culture. Significant differences were observed on self-kindness $(d=0.36)$ and over-identification $(d=2.49)$ subscales. The Turkish sample reported significantly higher levels of self-kindness and over-identification than the US sample.

Table 1

Means, SD, and effect sizes (d) for comparisons of self-compassion and components of SWB

\begin{tabular}{|c|c|c|c|c|c|}
\hline Variable & Sample & $M$ & $S D$ & $t$ & $d$ \\
\hline \multirow[t]{2}{*}{ Self-Compassion total-score } & Turkey & 3.10 & .50 & \multirow{2}{*}{-1.84} & \multirow{2}{*}{0.29} \\
\hline & US & 3.24 & .68 & & \\
\hline \multirow[t]{2}{*}{ Self-Kindness } & Turkey & 3.18 & .55 & \multirow{2}{*}{$2.24 *$} & \multirow{2}{*}{0.36} \\
\hline & US & 2.99 & .84 & & \\
\hline \multirow[t]{2}{*}{ Self-Judgment } & Turkey & 3.07 & .79 & \multirow{2}{*}{-.10} & \multirow{2}{*}{0.16} \\
\hline & US & 3.18 & .90 & & \\
\hline \multirow[t]{2}{*}{ Common-Humanity } & Turkey & 3.31 & .68 & \multirow{2}{*}{1.81} & \multirow{2}{*}{0.28} \\
\hline & US & 3.14 & .89 & & \\
\hline \multirow[t]{2}{*}{ Isolation } & Turkey & 3.11 & .76 & \multirow{2}{*}{.22} & \multirow{2}{*}{0.03} \\
\hline & US & 3.09 & .96 & & \\
\hline \multirow[t]{2}{*}{ Mindfulness } & Turkey & 3.41 & .80 & \multirow{2}{*}{2.01} & \multirow{2}{*}{0.28} \\
\hline & US & 3.22 & .83 & & \\
\hline \multirow[t]{2}{*}{ Over-Identification } & Turkey & 3.23 & .83 & \multirow{2}{*}{$23.01 *$} & \multirow{2}{*}{2.49} \\
\hline & US & 1.67 & .48 & & \\
\hline \multirow[t]{2}{*}{ Life Satisfaction } & Turkey & 4.60 & 1.17 & \multirow{2}{*}{$-2.59 * * *$} & \multirow{2}{*}{0.36} \\
\hline & US & 4.94 & 1.18 & & \\
\hline \multirow[t]{2}{*}{ Positive Affect } & Turkey & 5.39 & .92 & \multirow{2}{*}{$22.54 * * *$} & \multirow{2}{*}{2.79} \\
\hline & US & 3.38 & .74 & & \\
\hline \multirow[t]{2}{*}{ Negative Affect } & Turkey & 3.90 & 1.01 & \multirow{2}{*}{$26.21 * * *$} & \multirow{2}{*}{2.80} \\
\hline & US & 1.76 & .57 & & \\
\hline
\end{tabular}

Note. Turkish $(n=273)$ and US $(n=113)$. Name of the sample with significantly higher means are bolded. $* p<.05 . \quad * * * p<.001$ 
Sari, T., \& Conoley, C.

The correlations between self-compassion and components of subjective well-being are shown in Table 2 . The correlation results showed significant relationships between self-compassion and life satisfaction, as well as positive affect and negative affect among the Turkish sample and the US sample. In Table 2 the bold type denotes the magnitude of the correlations of self-compassion with life satisfaction, positive affect and negative affect. The correlations were similar but stronger for the US sample than the Turkish sample.

Table 2

Correlations between the different factors between Turkish and US samples

\begin{tabular}{|c|c|c|c|c|c|c|c|c|c|c|c|c|}
\hline \multirow{2}{*}{ Turkish sample $(\downarrow)$} & \multicolumn{12}{|c|}{ US sample $(\rightarrow)$} \\
\hline & 1 & 2 & 3 & 4 & 5 & 6 & 7 & 8 & 9 & 10 & 11 & 12 \\
\hline 1. Self-compassion & & $.90 * *$ & $-.84 * *$ & $.77 * *$ & $-.85 * *$ & $.87 * *$ & $-.76^{* *} *$ & $.33 * *$ & $.61 * *$ & $.44 * *$ & $.32 * *$ & $-.44 * *$ \\
\hline 2. Self-kindness & $.51 * *$ & & $-.74 * *$ & $.65^{* *}$ & $-.67 * *$ & $.79 * *$ & $-.64 * *$ & $.26^{* *}$ & $.57 * *$ & $.36^{* *}$ & $.34 * *$ & $-.39 * *$ \\
\hline 3. Self-judgment & -.072 & -.11 & & $-.47 * *$ & $.72 * *$ & $-.57 * *$ & $.65^{* *}$ & $-.28 * *$ & $-.51 * *$ & $-.34 * *$ & -.16 & $.43 * *$ \\
\hline 4. Common humanity & $.56^{* * *}$ & $.57 * *$ & $-.14 *$ & & $-.50 * *$ & $.73 * *$ & $-.42 * *$ & .16 & $.40 * *$ & $.29 * *$ & $.33 * *$ & $-.26 * *$ \\
\hline 5. Isolation & $-.63 * *$ & -.03 & $.60 * *$ & .01 & & $-.63 * *$ & $.65^{* *}$ & $-.37 * *$ & $-.57 * *$ & $-.43 * *$ & $-.23^{*}$ & $.38 * *$ \\
\hline 6. Mindfulness & $.63 * *$ & $.49 * *$ & $-.20 * *$ & $.50 * *$ & -.11 & & $-.60 * *$ & $.25 * *$ & $.52 * *$ & $.41 * *$ & $.31 * *$ & $-.32 * *$ \\
\hline 7. Over-identification & $-.66 * *$ & .02 & $.55 * *$ & -.03 & $.61 * *$ & $-.16^{* *}$ & & $-.33 * *$ & $-.48 * *$ & $-.35 * *$ & -.18 & $.46^{* *}$ \\
\hline 8. Positive relationships & $.37 * *$ & $.12 *$ & $-.35 * *$ & $.23^{* *}$ & $-.25 * *$ & $.16^{* *}$ & $-.22 * *$ & & $.48 * *$ & $.34 * *$ & $.37 * *$ & $-.45 * *$ \\
\hline 9. Self-acceptance & $.27 * *$ & .08 & $-.22 * *$ & $.23 * *$ & .07 & $.19 * *$ & -.10 & $.39 * *$ & & $.75^{* *}$ & $.52 * *$ & $-.51 * *$ \\
\hline 10. Life satisfaction & $.22 * *$ & $.13 *$ & $-.22 * *$ & $.16^{* *}$ & .12 & $.18 * *$ & -.03 & $.25^{* *}$ & $.34 * *$ & & $.49 * *$ & $-.44 * *$ \\
\hline 11. Positive affect & $.15^{*}$ & $.20 * *$ & -03 & $.21 * *$ & .11 & $.21 * *$ & .01 & $.33^{* *}$ & $.38 * *$ & $.35^{* *}$ & & -.15 \\
\hline 12. Negative affect & $-.40 * *$ & .08 & $.34 * *$ & $-.14 * *$ & $.29 * *$ & $-.21 * *$ & $.34 * *$ & $-.21 * *$ & $-.15 *$ & $-.13 *$ & .04 & \\
\hline
\end{tabular}

Correlations for the Turkish sample are below the diagonal, and for the US sample are above the diagonal. Significant correlations between independent variables and dependent variables are highlighted in bold. Following Cohen's (1992) formulation, correlations below .30 reflect a small effect size, above .30 represent a moderate effect size, and above .50 represent a large effect size.

The results of final question regarding mediation are presented in Table 3. In the analysis, the dependent variables were life satisfaction, positive affect and negative affect, which were predicted by the independent variable, self-compassion. Positive-relationships and self-acceptance were the potential mediators. Self-compassion was significantly associated with all of components of subjective well-being (c) and the mediators (a) in both Turkish and US samples. Positive-relationships with others was significantly associated with positive affect and negative affect in Turkish sample, but only with negative affect (b) in US sample. Self-acceptance was significantly associated life satisfaction and positive affect in Turkish sample and life satisfaction, positive affect and negative affect (b) in US sample. The direct effect of self-compassion on life satisfaction and positive affect (c') was not significant after entering the mediators into the model in the Turkish sample. In the US sample, the direct effect of self-compassion on life satisfaction, positive affect and negative affect (c') was not significant after the mediators entered the model.

Based on these results, in the Turkish sample, self-acceptance but not positive-relationships mediated the relationship between life satisfaction and self-compassion. Both self-acceptance and positive-relationships mediated the relationship between positive affect and self-compassion. Finally, neither self-acceptance nor positive-relationships mediated the relationship between negative affect and self-compassion.

In the US sample, neither self-acceptance nor positive-relationships mediated the relationship between life satisfaction and self-compassion. Self-acceptance but not positive-relationships mediated the relationship between positive affect and self-compassion. Finally, both self-acceptance and positive-relationships mediated the relationship between negative affect and self-compassion.

\section{Discussion}

The overall results provide information that reveals similarities and differences in understanding Neff's (2003a) self-compassion construct in the Turkey and US sample. The results indicated no difference between Turkish and US students on the total self-compassion scores. However, differences occurred within the 
self-compassion sub-scales. Turkish students had significantly higher scores on the self-kindness and over-identification sub-scales of self-compassion when compared to the US students. Similarities between cultures were generally supported by the similarity of correlations between the constructs of subjective well-being and self-compassion as predicted by self-compassion theory. The greatest differences were revealed by the mediation analyses. The mediation variables of self-acceptance and positive-relationships were mixed in explaining the relationship between self-compassion and the subjective well-being variables. However, the mediators' mixed results provided valuable information about cultural differences in self-compassion for Turkey and US.

Table 3

Summary of mediation results for study: Regression coefficients

\begin{tabular}{|c|c|c|c|c|c|c|c|}
\hline Sample & $\begin{array}{c}\text { Dependent } \\
\text { Variable (DV) }\end{array}$ & $\begin{array}{c}\text { Independent } \\
\text { Variable (IV) }\end{array}$ & Mediator (M) & $\begin{array}{c}\text { Effect of IV } \\
\text { on M (a) }\end{array}$ & $\begin{array}{l}\text { Effect of M } \\
\text { on DV (b) }\end{array}$ & $\begin{array}{l}\text { Total effects } \\
\text { (c) }\end{array}$ & $\begin{array}{c}\text { Direct } \\
\text { effects (c') }\end{array}$ \\
\hline \multirow{6}{*}{$\begin{array}{l}\text { Turkey } \\
\text { sample }\end{array}$} & Life & Self-Compassion & Positive-relationships & $.47 * * *$ & .19 & $.53 * * *$ & .26 \\
\hline & Satisfaction & & Self-acceptance & $.42 * * *$ & $.40 * * *$ & & \\
\hline & Positive Affect & & Positive-relationships & $.47 * * *$ & $.31 * *$ & $.28 *$ & -.02 \\
\hline & & & Self-acceptance & $.42 * * *$ & $.35 * * *$ & & \\
\hline & Negative & & Positive-relationships & $.47 * * *$ & -.09 & $-.81 * * *$ & $-.75^{*}$ \\
\hline & Affect & & Self-acceptance & $.42 * * *$ & -.03 & & \\
\hline \multirow{6}{*}{$\begin{array}{l}\text { US } \\
\text { sample }\end{array}$} & Life & & Positive-relationships & $.34 * *$ & -.04 & $.75 * * *$ & -.06 \\
\hline & Satisfaction & & Self-acceptance & $.83 * * *$ & $1.00 * * *$ & & \\
\hline & Positive Affect & & Positive-relationships & $.34 * *$ & .17 & $.34 * *$ & -.01 \\
\hline & & & Self-acceptance & $.83^{* * * *}$ & $.35 * * *$ & & \\
\hline & Negative & & Positive-relationships & $.34^{* *}$ & $-.20 * *$ & $-.37 * * *$ & -.15 \\
\hline & Affect & & Self-acceptance & $.83 * * *$ & $-.17 * *$ & & \\
\hline
\end{tabular}

Note. $* p<.05 . \quad * * p<.01 . \quad * * * p<.001$.

The first results discussed are the comparisons of self-compassion means of the Turkish and US samples. The total self-compassion scores were not statistically different between the Turkish and US students. The similarity of self-compassion means was important initial step in support of similarities between cultures. However, a deeper examination comparing the sub-scales of the total self-compassion scores revealed differences that suggest differences in self-compassion across cultures. The Turkish students were significantly higher on the self-kindness and over-identification sub-scales of self-compassion scores when compared to the US students. While the two subscales are higher in the Turkey sample, the total self-compassion score includes adding self-kindness sub-scale and subtracting the over-identification sub-scale. The two higher sub-scales cancel each other out in the total self-compassion score. Neff (2003) considers the over-identification sub-scale a negative dimension of self-compassion because over-identification is the tendency to ruminate on negative feelings and thoughts thereby allowing the negativity to have inordinate influence. The Turkish students ruminated with negative feelings towards their problems (i.e. over-identification), while having a kind and gentle attitude towards themselves (i.e. self-kindness). Culture provides explanations for the differences in self-compassion sub-scales. The US students' lower self-kindness scores may occur due to the higher value on competition and individual achievement in the US's individualistic culture (Diener \& Diener, 1995). Therefore, US students may regard problems as personal failures resulting in self-condemnation that lowers self-kindness. The Turkish students' lower competitive attitude may allow freedom from this source of self-condemnation and increase their self-kindness scores.

This study is not the first to find culture interacting with the sub-scales of the larger construct of self-compassion. In the East Asian culture of Japan, Kitayama and Karasawa (1997) found their sample was high in both positive emotions towards themselves and were self-judgmental. Heine, Lehman, Markus and Kitamaya (1999) argued that self-judgment, which is described as a negative sub-scale of self-compassion (Neff, 2003), may not constitute a problem for the individuals of some collectivist cultures.

The second results discussed are the significant correlations between self-compassion and the constructs making up subjective well-being for both the Turkey and US sample. The results support self-compassion operating similarly in both cultures because all of the correlations were significant as predicted by 
self-compassion theory. Interestingly, the correlations between self-compassion and the subjective well-being constructs of the US sample were consistently stronger than the Turkish sample. The stronger relationship between self-compassions constructs and the subjective well-being constructs for the US students suggests that increasing self-compassion to influence subjective well-being could be more effective for US students than Turkish students. These results are in line with the previous research of Neff, Pisitsungkagarn, and Hsieh (2008) that found self-compassion a better predictor of life satisfaction in America than Thailand. Self-compassion may be more strongly associated with subjective well-being in individualistic cultures than in collectivist cultures.

The other results discussed are the mediation models. The construct self-compassion correlates with SWB across cultures. However, the mediators that explain why the correlations occur are not found to be the same. Out of the six comparisons, only three were cross-culturally consistent. That is, there were differences in the mediators explaining how self-compassion was related to the variables of subjective well-being between Turkey and US in half the comparisons.

Specifically, for both Turkey and US self-acceptance mediated the relationship between self-compassion and both positive affect and life satisfaction. That is, self-acceptance explained why self-compassion correlates with positive affect and life satisfaction for students in both Turkey and the US. However, only in the US sample did self-acceptance mediate or explain the relationship between self-compassion and negative affect. The dynamics of self-compassion influencing negative affect was different for the two samples. Two of the three comparisons using the mediator of self-acceptance were similar.

The second mediator examined was positive-relationships. Positive-relationships revealed even greater cross-cultural differences than self-acceptance. Positive-relationships mediated or explained the relationship between self-compassion and positive affect in the Turkish but not the US sample. And positive-relationships mediated the relationship between self-compassion and negative affect in the US but not the Turkish sample. Positive-relationships did not mediate the relationship between self-compassion and life satisfaction for either country. The dynamics of self-compassion influencing negative affect and positive affect was different for the two samples. Only one of the three comparisons using the mediator of positive-relationships was similar. Positive-relationships with others have important roles, but they operate differently in these two cultures.

The finding that positive-relationships lead to an increase in positive emotions in Turkish sample can be explained by considering Turkey a collectivist culture. Studying the effects of culture and self-construal on cognition and emotion, Markus and Kitayama (1991) determined that the individuals from collectivist cultures such as Asia, Latin America, and Africa had an interdependent-relational self-construal that places a great deal of importance on interpersonal relationships, other individuals and social approval. Emotional support from others was found to be more important in collectivist Asian cultures in terms of subjective well-being compared to individualistic US culture (Uchida, Kitamaya, Mesqiata, Reyes, \& Morling, 2008). Therefore, the creation of positive-relationships by self-compassion should increase positive emotions more in a collectivist culture.

There are limitations in this study that could inform future studies. First, the sample groups were obtained from specific regions in both countries. US and Turkish cultures consist of various lifestyles and sub-cultures depending on their geographical location. Therefore, it is necessary to be cautious when generalizing from one specific study. Future studies should include strategically different sample groups. Future cross-cultural comparison studies could use mixed models in addition to the present research model to possibly add greater understanding about the statistical relationships. Future studies should investigate the role of these mediator variables plus additional ones. Finally, future studies could directly measure self-construal and relevant demographic variables such as socio-economic status.

In conclusion, the findings of this study provide new perspectives of self-compassion in different cultures. While the total self-compassion scores were similar when comparing Turkey and US samples, the self-compassion sub-scales of self-kindness and over-identification were significantly different between cultures. Future research should further examine the differential functioning of the sub-scales of self-compassion 
cross-culturally. The correlations between self-compassion and subjective well-being suggest that self-compassion functions as predicted in both cultures. However, when examining why self-compassion correlates with subjective well-being variables the theory is not supported. That is, the reason self-compassion is correlated to subjective well-being has differences between the Turkey and US samples. Future research should replicate this finding.

The mediators suggested that self-compassion functions differently in the two countries. The universal mediator across cultures was self-acceptance. Self-acceptance explained why self-compassion and subjective well-being are associated for both Turkey and US. The only exception is that self-acceptance did not explain the relationship between self-compassion and negative affect in the Turkey sample. Positive-relationships was the mediator that revealed the largest differences across cultures. Positive-relationships mediated the relationship between self-compassion and positive affect in the Turkish but not the US sample. Positive-relationships mediated the relationship between self-compassion and negative affect in the US but not the Turkish sample. However, positive-relationships did not mediate the relationship between self-compassion and life satisfaction for either country. Future research should search for a mediator for explaining the relationship between self-compassion and life satisfaction especially for Turkey. The differences between Turkey and US in relation to the mediator of positive-relationships are not surprising because of the differences in self-construal in the two countries. In conclusion, this research revealed that generally self-compassion is similar in Turkey and the US; however, the manner in which self-compassion influences the major mental health goals has differences. Interventions involving self-compassion should be alert to cultural differences.

Mediator results reveal that self-acceptance has a universal mediator role in the relationship between self-compassion and life satisfaction, whereas positive-relationships with others have a mediator role in the relationship of self-compassion with positive emotions in Turkish culture, and in the relationship between self-compassion with negative emotions in US culture, and therefore, they are important factors in terms of subjective well-being in both cultures. Student personality services should be rendered in order to increase the life satisfaction levels of university students who pass through a stressful period. In this regard, the findings of this study can be utilized in training and counseling studies carried out for the students. In addition, the findings of this study may provide ideas to the researchers who will conduct studies on both Turkish and US culture in future. No comparison study has been conducted on self-compassion in Turkish and US samples so far. Results indicate that while self-compassion is differently emphasized by cultures, its beneficial implications for well-being can be universal. In this regard, it is believed that this study could make significant contributions to the intercultural studies.

\section{References}

Akın, A. (2008). Self-compassion and achievement goals: A structural equation modeling approach. Eurasian Journal of Educational Research, 31, 1-15.

Akın, A. (2010a). Self-compassion and interpersonal cognitive distortions. Hacettepe University Journal of Education Faculty, 39, 1-9.

Akın, A. (2010b). Self-compassion and loneliness. International Online Journal of Educational Science, 2(3), $702-718$.

Akın, A. (2012). Self-compassion and automatic thoughts [In Turkish]. Hacettepe University Journal of Education Faculty, 42, 1-10.

Akın, A. Demirci, İ., Yıldız, E., Gediksiz, E., \& Eroğlu, N. (2012). The short form of the scales of psychological well-being (SPWB-42): The validity and reliability of the Turkish version. Paper presented at the International Counseling and Education Conference, May, 3-5, İstanbul.

Akın, A., Kayış, A. R., \& Satıcı, S. A. (2011). Self-compassion and social support. Paper presented at the International conference on new trends in education and their implications, Antalya, Turkey.

Akın, Ü. (2014). The predictive role of the self-compassion on psychological vulnerability in Turkish university students. International Journal of Social Science \& Education, 4(3), 693-701. 
Sari, T., \& Conoley, C.

Akın, Ü., Akın, A., \& Abacı, R. (2007). Self-compassion scale: Validity and reliability studies. Hacettepe University Journal of Education Faculty, 33, 1-10.

Akkaya, Ç. (2011). Perceived social support and self-sensitivity levels in secondary education levels [In Turkish]. (Masteral thesis). Sakarya University, Sakarya, Turkey.

Arimitsu K. (2014). Development and validation of the Japanese version of the Self-Compassion Scale. Japanese Journal of Psychology, 85, 50-59. https://doi.org/10.4992/jipsy.85.50

Arthaud-Day, M. L., Rode, J.C., Mooney, C. H., \& Near, J. P. (2005). The subjective well-being construct: A test of its convergent, discriminant, and factorial validity. Social Indicators Research, 74, 445-476. https://doi.org/10.1007/s11205-004-8209-6

Biswas-Diener, R., Diener, E., \& Tamir, M. (2004). The psychology of subjective well-being. Daedalus, 133, 18-25. https://doi.org/10.1162/001152604323049352

Campos, D., Cebolla, A., Quero, S., Bretón-López, J., Botella, C, Soler, J., García-Campayo, J., Demarzo, M., \& Baños, R. M. (2016). Meditation and happiness: Mindfulness and self-compassion may mediate the meditation-happiness relationship. Personality and Individual Differences, 93, 80-85. https://doi.org/10.1016/j.paid.2015.08.040

Cenkseven, F. (2004). Investigation of the predictors of psychological well-being among university students [In Turkish]. (Doctoral thesis). Çukurova University, Adana, Turkey.

Conway, D. G. (2007). The role of internal resources in academic achievement: Exploring the meaning of self-compassion in the adaptive functioning of low-income college students. (Doctoral dissertation). University of Pittsburgh, USA.

Deniz, M. E., \& Sümer, A. S. (2010). Investigation of depression, anxiety and stress among university students with different levels of self-compassion [In Turkish]. Education and Science, 35(158), 155-127.

Deniz, M. E., Arslan, C., Özyeşil, Z., \& İzmirli, M. (2012). Self-compassion, life satisfaction, negative and positive emotion: A comparison between Turkish and other country university students. [In Turkish]. Mehmet Akif Ersoy University Journal of Education Faculty, 12(23), 428-446.

Deniz, M. E., Kesici Ş., \& Sümer A. S. (2008) The Validity and Reliability Study of the Turkish Version of Self-Compassion Scale. Social Behavior and Personality: An International Journal, 36(9), 1151-1160. https://doi.org/10.2224/sbp.2008.36.9.1151

Diener, E. (1984). Subjective well-being. Psychological Bulletin, 95(3), 542-575. https://doi.org/10.1037/0033-2909.95.3.542

Diener, E. (2000). Subjective well-being: The science of happiness and a proposal for a national index. US Psychologist, 55(1), 34-43. https://doi.org/10.1037/0003-066X.55.1.34

Diener, E. (2006). Guidelines for national indicators of subjective well-being and ill-being. Applied Research in Quality of Life, 1, 151-157. https://doi.org/10.1007/s11482-006-9007-x

Diener, E., \& Diener, M. (1995). Cross-cultural correlates of life satisfaction and self-esteem. Journal of Personality and Social Psychology, 68, 653-663. https://doi.org/10.1037/0022-3514.68.4.653

Diener, E., \& Lucas, R. E. (1999). Subjective well-being: Three decades of progress. Psychological Bulletin, 125(2), 276-303. https://doi.org/10.1037/0033-2909.125.2.276

Diener, E., Emmons, R. A., Larsen, R. J., \& Griffin, S. (1985). The satisfaction with life scale. Journal Personality and Social Psychology, 68, 653-663. https://doi.org/10.1207/s15327752jpa4901_13

Diener, E., Suh, E. M., Lucas, R. E., \& Smith, H. E. (1999). Subjective well-being: Three decades of progress. Psychological Bulletin, 125, 276-302. https://doi.org/10.1037/0033-2909.125.2.276

Diener, E., Suh, E., \& Oishi, S. (1997). Recent findings on subjective well-being. Indian Journal of Clinical Psychology, 24, 25-41.

Folkman, S., \& Moskowitz, J. T. (2000). Positive affect and the other side of coping. US Psychologist, 55(6), 647-654. https://doi.org/10.1037/0003-066X.55.6.647

Garcia-Campayo, J., Navarro-Gil, M., Andrés, E., Montero-Marin, J., López-Artal, L., \& Demarzo, M. M. (2014). Validation of the Spanish versions of the long (26 items) and short (12 items) forms of the Self-Compassion Scale (SCS). Health and Quality of Life Outcomes, 12(1), 4. https://doi.org/10.1186/1477-7525-12-4 
Relationship between self-compassion and well-being: A comparison of Turkish and US university students

Gencoz, T. (2000). Positive and negative affect schedule: A study of validity and reliability. Turkish Journal of Psychology, 15, 19-28. https://doi.org/10.1590/1516-4446-2012-0957

Ghorbani, N., Watson, P. J., Chen, Z., \& Norballa, F. (2012). Self-compassion in Iranian Muslims: relationships with integrative self-knowledge, mental health, and religious orientation. International Journal for the Psychology of Religion, 22(2), 106-118. https://doi.org/10.1080/10508619.2011.638601

Göregenli, M. (1995). Individualism - Collectivism orientations in the Turkish culture: A preliminary study. Turkish Psychology Journal, 10, 1-14.

Göregenli, M. (1997). Individualist and collectivist tendencies in a Turkish sample. Journal of Cross-Cultural Psychology, 28, 787-794. https://doi.org/10.1177/0022022197286009

Heine, S. J., Lehman, D. R., Markus, H. R., \& Kitayama, S. (1999). Is there a universal need for positive self-regard? Psychological Review, 106, 766-794. https://doi.org/10.1037//0033-295X.106.4.766

Hortacsu, N. (1997). Cross-cultural comparison of need importance and need satisfaction during adolescents: Turkey and the United States. Journal of Genetic Psychology, 158, 287-297. https://doi.org/10.1080/00221329709596668

İkiz, E., \& Totan, T. (2012). Investigation of self-compassion and emotional intelligence among university students. Dokuz Eylul University Journal of Graduate School of Social Sciences, 14(1), 51-71.

İmamoğlu, E. 0., \& Yasak, Y. (1997). Dimensions of marital relations as perceived by Turkish husbands and wives. Genetic, Social and General Psychology Monographs, 123, 211-232.

Isen, A. M. (2000). Some perspectives on positive affect and self-regulation. Psychological Inquiry, 11, 184-188.

İskender, M. (2009). The relationship between self-compassion, self-efficacy and control belief about learning in Turkish university students. Social Behavior and Personality, 37(5), 711-720. https://doi.org/10.2224/sbp.2009.37.5.711

İskender, M., \& Akın, A. (2011). Self-Compassion and Internet Addiction, TOJET: The Turkish Online Journal of Educational Technology 10(3), 215-221.

Kağıtçıbaşı, Ç. (1987). Individualism and collectivism. A universal dimension? In Ç. Kağıtçıbaşı (Eds.) Growth and progress in cross-cultural psychology (pp. 135- 200). Lincoln: University of Nebraska Press.

Kağıtç̧başı, Ç. (1999). Again human and human beings. [In Turkish]. İstanbul: Evrim Press.

Kağıtçıbaşı, Ç. (2000). Cultural psychology. Human and family in the context of culture [In Turkish]. İstanbul: Evrim Press.

Kağıtçıbaşı, C. (2005). Autonomy and relatedness in cultural context: Implications for self and family. Journal of Cross-Cultural Psychology, 36, 403-422. https://doi.org/10.1177/0022022105275959

Keyes, C. L. M., Shmotkin, D. \& Ryff, C. D. (2002). Optimizing well-being: The empirical encounter of two traditions. Journal of Personality \& Social Psychology, 82(6) 1007- 1023. https://doi.org/10.1037/0022-3514.82.6.1007

Kim, H., Schimmack, U., Cheng, C., Webster, G. D., \& Spectre, A. (2016). The role of positive self-evaluation on cross-cultural differences in well-being. Cross-Cultural Research, 50, 85-99. https://doi.org/10.1177/1069397115617902

Kingsbury, E. (2009). The relationship between empathy and mindfulness: Understanding the role of self-compassion. Dissertation Abstracts International: Section B: The Sciences and Engineering, 70(5-B), 3175 .

Kirkpatrick, K. L. (2005). Enhancing self-compassion using a gestalt two-chair intervention. (Doctoral dissertation). University of Texas, Austin, USA.

Kitayama, S., \& Karasawa, M. (1997). Implicit self-esteem in Japan: Name letters and birthday numbers. Personality \& Social Psychology Bulletin, 23, 736-742. https://doi.org/10.1177/0146167297237006

Kitayama, S., \& Markus, H. R. (2000). The pursuit of happiness and the realization of sympathy: Cultural patterns of self, social relations, and well-being. In E. Diener \& E. M. Suh (Eds.), Culture and subjective wellbeing (pp. 113-161). Cambridge, MA: MIT Press.

Kitayama, S., \& Uchida, Y. (2003). Explicit self-criticism and implicit self-regard: Evaluating self and friend in two cultures. Journal of Experimental Social Psychology, 39, 476-482.

https://doi.org/10.1016/S0022-1031(03)00026-X 
Sari, T., \& Conoley, C.

Kitayama, S., Markus, H. R., Matsumoto, H., \& Norasakkunkit, V. (1997). Individual and collective processes in the construction of the self: Self-enhancement in the United States and self-criticism in Japan. Journal of Personality and Social Psychology, 72, 1245-1267. https://doi.org/10.1037/0022-3514.72.6.1245

Köker, S. (1991). Comparison of life satisfaction levels of normal and troubled adolescents [In Turkish]. (Masteral thesis). Ankara University, Ankara, Turkey.

Koydemir, S., \& Schutz, A. (2012). Emotional intelligence predicts components of subjective well-being beyond personality: A two-country study using self- and informant reports. The Journal of Positive Psychology, 7, 107-118. https://doi.org/10.1080/17439760.2011.647050

Koydemir, S., Şimşek, O. F., Schutz, A., \& Tipandjan, A. (2013). Differences in how trait emotional intelligence predicts life satisfaction: The role of affect balance versus social support in India and Germany. Journal of Happiness Studies, 14, 51-66. https://doi.org/10.1007/s10902-011-9315-1

Kuppens, P., Realo, A., \& Diener, E. (2008). The role of positive and negative emotions in life satisfaction judgments across nations. Journal of Personality and Social Psychology, 95, 66-75. https://doi.org/10.1037/0022-3514.95.1.66

Kuyumcu, B., \& Güven, M. (2012). The relationship between Turkish and English university students' perception and expression of emotions and psychological well-being [In Turkish]. Gazi University Journal of Education Faculty, 32, 589-607.

Leary, M. R., Tate, E. B., Adams, C. E., Allen, A. B. \& Hancock, J. (2007). Self-compassion and reactions to unpleasant self-relevant events: The implications of treating one-self kindly. Journal of Personality and Social Psychology, 92, 887-904. https:// doi.org/10.1037/0022-3514.92.5.887

Lucas, R.E., \& Diener, E. (2004). Encyclopedia of applied psychology. In C. Spielberger (Ed.), Well-being (pp. 669-676). Elsevier Academic Pres. https://doi.org/10.1016/B0-12-657410-3/00174-4

Lyubomirsky, S., King, L., \& Diener, E. (2005). The benefits of frequent positive effect: Does happiness lead to success. Psychological Bulletin, 131, 803-855. https://doi.org/10.1037/0033-2909.131.6.803

Markus, H. R., \& Kitayama, S. (1991). Culture and self: Implications for cognition, emotion and motivation. Psychological Review, 98, 224-253. https://doi.org/10.1037/0033-295X.98.2.224

Matsumoto, D., Consolacion, T., Yamada, H., Suzuki, R., Franklin, B., Paul, S., Ray, R., \& Uchida, H. (2002). US-Japanese cultural differences in judgments of emotional expressions of different intensities. Cognition \& Emotion, 16(6), 721-747. https://doi.org/10.1080/02699930143000608

Mocan-Aydın, G. (2000). Western models of counseling and psychotherapy within Turkey: Crossing cultural boundaries. The Counseling Psychologist, 28, 281- 298. https://doi.org/10.1177/0011000000282007

Myers, D. G., \& Diener, E. (1995). Who is happy? Psychological Science, 6, 10-19. https://doi.org/10.1111/j.1467-9280.1995.tb00298.x

Neff, K. D. (2003a). Development and validation of a scale to measure self-compassion. Self and Identity, 2, 223-250. https://doi.org/10.1080/15298860309027

Neff, K. D. (2003b). Self-compassion: An alternative conceptualization of a healthy attitude toward oneself. Self and Identity, 2, 85-102. https://doi.org/10.1080/15298860309032

Neff, K. D. (2004). Self-compassion and psychological well-being. Constructivism in the Human Sciences, 9(2), 27-37.

Neff, K. D. (2008). Self-compassion: Moving beyond the pitfalls of a separate self- concept. In J. Bauer \& H. A. Wayment (Eds.). Transcending self-interest: Psychological explorations of the quiet ego (pp. 95-106). Washington, DC: APA Books. https://doi.org/10.1037/11771-009

Neff, K. D. (2009). Self-Compassion. In M. R. Leary \& R. H. Hoyle (Eds.), Handbook of individual differences in social behavior (pp. 561-573). New York: Guilford Press.

Neff, K. D. (2011). Self-compassion, self-esteem and well-being. Social and Personal Psychology Compass, 5(1), 1-12. https://doi.org/10.1111/j.1751-9004.2010.00330.x

Neff, K. D. Hsieh,Y., \& Dejitterat., K. (2005). Self-compassion, achievement goals, and coping with academic failure. Self and Identity, 4, 263-287. https://doi.org/10.1080/13576500444000317

Neff, K. D., \& Davidson, O. (2016). Self-compassion. Embracing suffering with kindness. In I. Ivtzan \& T. Lomas (Eds.), Mindfulness in positive psychology: The science of meditation and wellbeing (pp. 14-26). 
Abington: Routledge.

Neff, K. D., \& McGeehee, P. (2010). Self-compassion and psychological resilience among adolescents and young adults. Self and Identity, 9, 225-240. https://doi.org/10.1080/15298860902979307

Neff, K. D., \& Pommier, E. (2013). The relationship between self-compassion and other-focused concern among college undergraduates, community adults, and practicing meditators. Self and Identity, 12(2), 160-176. https://doi.org/10.1080/15298868.2011.649546

Neff, K. D., Kirkpatrick, K. L. \& Rude, S.S., (2007). Self-compassion and adaptive psychological functioning. Journal of Research in Personality, 41, 139-154. https://doi.org/10.1016/j.jrp.2006.03.004

Neff, K. D., Pisitsungkagarn, K., \& Hsieh, Y. (2008). Self-compassion and self-construal in the United States, Thailand, and Taiwan. Journal of Cross-Cultural Psychology, 39, 267-285. https://doi.org/10.1177/0022022108314544

Neff, K. D., Rude, S. S., \& Kirkpatrick, K.L. (2007). An examination of self-compassion in relation to positive psychological functioning and personality traits. Journal of Research in Personality, 41(4), 908-916. https://doi.org/10.1016/j.jrp.2006.08.002

Neff, K. D. (2011). Self-compassion. New York: Harper Collins Publishers.

Neff, K. D. (2012). The science of self-compassion. In C. Germer \& R. Siegel (Eds.), Compassion and wisdom in psychotherapy (pp. 79-92). New York: Guilford Press.

Özer, M., \& Karabulut, Ö. Ö. (2003). Life satisfaction in elderly people [In Turkish]. Turkish Journal of Geriatrics, 6(2), 72-74.

Preacher, K. J., \& Hayes, A. F. (2008). Asymptotic and resampling strategies for assessing and comparing indirect effects in multiple mediator models. Behavior research Methods, 40(3), 879-891. https://doi.org/10.3758/BRM.40.3.879

Rogers, C. R. (1961). On becoming a person: A psychotherapist's view of psychotherapy. Washington, DC: Houghton Mifflin.

Ryan, M. R., \& Deci, E. L. (2000). Self-determination theory and the facilitation of intrinsic motivation, social development, and well-being. US Psychologist, 55(1), 68-78. https://doi.org/10.1037/0003-066X.55.1.68

Ryff, C. D. (1989). Happiness is everything, or is it? Explorations of the meaning of psychological wellbeing. Journal of Personality and Social Psychology, 57, 1069-1081. https://doi.org/10.1037/0022-3514.57.6.1069

Ryff, C. D. (1995). Psychological well-being in adult life. Current Directions in Psychological Science, 4(4), 99-104. https://doi.org/10.1111/1467-8721.ep10772395

Ryff, C. D., \& Keyes, C. L. M. (1995). The structure of psychological well-being revisited. Journal of Personality and Social Psychology, 69(4), 719- 727. https://doi.org/10.1037/0022-3514.69.4.719

Ryff, C. D., \& Singer, B. H. (2008). Know thyself and become what you are: A eudemonic approach to psychological well-being. Journal of Happiness Studies, 9(1), 13-39. https://doi.org/10.1007/s10902-006-9019-0

Sarıcıoğlu, İ. (2011). Examination of psychological well-being of university students in terms of personality traits and self-compassion [In Turkish]. (Masteral thesis). Selçuk University, Turkey.

Solomon, S., Greenberg, J. L., \& Pyszczynski, T. (1991). A terror management theory of social behavior: The psychological functions of self-esteem and cultural worldviews. Advances in Experimental and Social Psychology, 24, 93-159. https://doi.org/10.1016/S0065-2601(08)60328-7

Tel, D., \& Sarı, T. (2016). Self-compassion and life satisfaction among university students. Abant Izzet Baysal University Journal of Education Faculty, 16(1), 292-304.

Tezcan, M. (1987). Culture and personality [In Turkish]. Ankara: Bilim Press.

Uchida, Y., \& Ogihara, Y. (2012). Personal or interpersonal construal of happiness: A cultural psychological perspective. International Journal of Wellbeing, 2, 354-369. https://doi.org/10.5502/ijw.v2.i4.5

Uchida, Y., Kitayama, S., Mesquita, B., Reyes, J. A. S., \& Morling, B. (2008). Is perceived emotional support beneficial? Well-being and health in independent and interdependent cultures. Personality and Social Psychology Bulletin, 34, 741-754. https://doi.org/10.1016/j.sbspro.2012.09.543 
Sari, T., \& Conoley, C.

Watson, D., Clark, L. A., \& Tellegen, A. (1988). Development and validation of brief measures of positive and negative affect: The PANAS scales. Journal of Personality and Social Psychology, 54, 1063-1070. https://doi.org/10.1037/0022-3514.54.6.1063

Williams, J. G., Stark, S. K., \& Foster, E. E. (2008). Start today or the very last day? The relationships among self-compassion, motivation, and procrastination. US Journal of Psychological Research, 4, 37-44.

Wirtz, D., Chiu, C. Y., Diener, E., \& Oishi, S. (2009). What constitutes a good life? Cultural differences in the role of positive and negative affect in subjective well-being. Journal of Personality, 77, 1167-1196. https://doi.org/10.1111/j.1467-6494.2009.00578.x

Zessin, U. Dickhauser, O., \& Garbade, S. (2015). The relationship between self-compassion and well-being: A meta-analysis. Applied Psychology: Health and Well-Being, 7(3), 340-364.

https://doi.org/10.1111/aphw.12051 